\title{
Bacteroidetes Help Hosts Harvest More Energy from High Fiber Diets
}

\author{
Xue bin ${ }^{1}$, Pingru Liu ${ }^{1}$ and Gang $\mathrm{Wu}^{2,3 *}$ \\ ${ }^{1}$ School of Engineering, Guangzhou College of Technology and Business, \\ Guangzhou, China \\ ${ }^{2}$ Department of Food, Wine, and Molecular Bioscience, Lincoln University, \\ Christchurch, New Zealand \\ ${ }^{3}$ Riddet Institute, Palmerston North, New Zealand \\ *Corresponding Author: Gang Wu, Department of Food, Wine, and Molecular \\ Bioscience, Lincoln University, Christchurch, New Zealand and Riddet Institute, \\ Palmerston North, New Zealand.
}

DOI: $10.31080 /$ ASNH.2022.06.1010

\begin{abstract}
Obesity has been associated with imbalance of gut microbiota. The objective of this study was to investigate the role of gut microbiota in host's harvesting energy. During the period of 8 weeks' feeding of the high-soybean-fiber (HSF) diet or the high-fructooligosaccharide (HFOS) diet, the rats' body weight (BW), gut microbiota composition, short chain fatty acids (SCFAs) in feces, plasma lipopolysaccharide (LPS) and leptin were measured at week 0, 4 and 8 . The results presented high dietary fibers (HDFs) can up-regulate the abundance of Bacteroidetes in rats' gut. Since Bacteroidetes can hydrolyze complex carbohydrates to release energy, such as SCFAs, lean rats, more Bacteroidetes growing in their gut, gained more body weight than the obese ones when they both consumed the same HDF diets. The fluctuations of plasma LPS and leptin individually kept consistent with that of the abundance of Gram-negative bacteria in feces and rats' BW gain. Hence, Bacteroidetes in gut is the key one to help hosts harvest more energy from HDFs diet.
\end{abstract}

Keywords: Obesity; Gut Microbiota; Short Chain Fatty Acids; Lipopolysaccharide; Leptin

\section{Abbreviations}

BW: Body Weight; HDF: High Dietary Fiber; HFOS: High Fructooligosaccharide; HSF: High Soybean Fiber; LPS: Lipopolysaccharide; SCFAs: Short Chain Fatty Acids

\section{Introduction}

Obesity is well-recognized as a global epidemic and is associated with various co-morbidities, including hypertension [1], insulin resistance and other components of the metabolic syndrome [2]. More recently, obesity is even recognized as a risk factor for cancer [3]. For the past decade, obesity has been associated with imbalance of gut microbiota [4], and studies have widely reported that obese hosts have higher Firmicutes/Bacteroidetes ratio [5]. The mechanisms by which gut microbiota affects obesity in humans are complicated and largely unknown [6]. But several statements have been proposed: 1) an excessive bodily energy harvest, 2) higher levels of SCFAs to promote adipogenesis, 3) overexpression of the obesity-related genes, and 4) increased production of LPS by gut microbiota causing obesity and inflammation [7]. Besides, a connection had also been reported between plasma leptin concentrations and the composition of the gut microbiota [8].

Diet plays a crucial role in shifting intestinal microbiota. Turnbaugh, Ley, Mahowald, Magrini, Mardis and Gordon [9] has reported that the modern western diet consisting of more animal fat and less vegetables and fiber could induce more Firmicutes than Bacteroidetes in mice guts, and hence resulted in an increased capacity for the fermentation of carbohydrates [10]. However, it is still extensively disputed about the role of gut microbiota, especially Firmicutes and Bacteroidetes, in host harvesting energy from diets $[11,12]$.

The objective of the present study was to investigate which phyla of gut microbiota can help the host obtain more energy from two high-dietary-fiber (HDF) diets and how they work. The two dietary fibers involved were soybean fiber, which is a partially soluble 
mixed fiber, and fructooligosaccharide (FOS), which was soluble and often utilized as prebiotics.

\section{Materials and Methods}

Animal, diets, feces sample preparation, and fecal bacteria analysis

The models of lean and obese male Sprague Dawley rats (5-6 weeks old) (Guangdong Medical Laboratory Animal Center, Foshan, China) were built by feeding normal feed and high-fat diet; feces samples were collected and fecal bacteria were isolated and identified by the methods mentioned in a previous reports [13]. Briefly, rats were assigned to four experimental groups (10 rats for each group), and were fed the high-soybean-fiber (HSF) diet or the highFOS (HFOS) diet: 1) SL group: lean rats were fed the HSF diet for 8 weeks; 2) FL group: lean rats were fed the HFOS diet for 8 weeks; 3) SO group: obese rats were fed the HSF diet for 8 weeks; 4) FO group: obese rats were fed the HFOS diet for 8 weeks. SL and FL groups were in turns the controls of SO and FO groups. Fresh fecal specimens were collected at week 1 (defined as I), week 5 (defined as II) and week 9 (defined as III). This experiment has been approved by the animal ethics committee of Jinan University.

\section{Determination of SCFA in feces}

SCFA concentrations in fecal specimens were measured as follows [14]: an aliquot of $200 \mathrm{mg}$ of each stool sample was weighed. This was suspended in sterile distilled water $(1.6 \mathrm{~mL})$ and hexanoic acid $(0.2 \mathrm{~mL})$ was added. About $50 \%$ aqueous $\mathrm{H}_{2} \mathrm{SO}_{4}(0.4 \mathrm{~mL})$ and diethyl ether ( $2 \mathrm{~mL}$ ) were then added. The sample was mixed for 45 min with an orbital shaker and centrifuged for 5 min at 3000 rpm at room temperature. Anhydrous $\mathrm{CaCl}_{2}$ was then added in order to remove residual water, and $2 \mu \mathrm{L}$ of the extracts were injected in the GC 2010 gas chromatograph with a flame ionization detector (Shimadzu, Tokyo, Japan). The GC column was a DB-FFAP (Agilent Technologies, Waldbronn, Germany), length $30 \mathrm{~m}$, and internal diameter $0.46 \mathrm{~mm}$, film thickness $0.25 \mu \mathrm{m}$. The GC was programmed to achieve the following run parameters: initial temperature 120 ${ }^{\circ} \mathrm{C}$, hold $5.0 \mathrm{~min}$, ramp $15{ }^{\circ} \mathrm{C} / \mathrm{min}$, final temperature $250{ }^{\circ} \mathrm{C}$, and total run time $8.0 \mathrm{~min}$. Gas flow $7.7 \mathrm{~mL} / \mathrm{min}$ splitless to maintain 3.26 psi column head pressure, septum purge $2.0 \mathrm{~mL} / \mathrm{min}$.

Calibration standards were prepared to give a mixture of the following concentrations of acids (mM): 26.22 acetic, 19.86 propionic and 16.32 butyric. This standard mix $(0.2 \mu \mathrm{L})$ was used to calculate retention times and create a standard plot. Additional standards were included in each GC run of samples at five sample intervals to maintain calibration; $0.2 \mu \mathrm{L}$ of each subsample distillate was analyzed by GC and an integrator was used to plot the curve of the standards and provide the concentration of acids present in mM.

\section{Determination of serum LPS}

LPS was measured with a Pyrochrome Lysate Mix, a quantitative chromogenic reagent (Associate of Cape Cod, East Falmouth, MA). Briefly, plasma samples were diluted 1:10 in pyrogen-free water (Associate of Cape Cod) and heated for $10 \mathrm{~min}$ at $70^{\circ} \mathrm{C}$. Samples and reactive solution were incubated at $37^{\circ} \mathrm{C}$ for $30 \mathrm{~min}$, and absorbance was read at $405 \mathrm{~nm}$.

\section{Determination of serum leptin}

Blood for leptin assays was collected into EDTA anticoagulant tubes, following by 10 -min centrifugation at $2,000 \mathrm{rpm}$ within 30 min. Plasma was collected at $4{ }^{\circ} \mathrm{C}$ and frozen at $-80^{\circ} \mathrm{C}$ until time of assay. Leptin was assayed using the Quantikine ELISA kit (R and D Systems, Minneapolis, MN).

\section{Statistical analysis}

Results are expressed as mean values and standard deviations. The statistical analysis was performed with SPSS 17.0 software (SPSS Inc., Chicago, IL). ANOVA were conducted to compare the difference between groups and all statistical tests were two-tailed. Statistical significance was set at a P value of $<0.05$.

\section{Results and Discussion}

Relationship between BW gain and ratio of Firmicutes to Bacteroidetes

During the period of ingesting high-dietary-fiber diets, the Firmicutes/Bacteroidetes ratio in all groups showed a declining trend (Figure 1). As Bacteroidetes were seldom detected in Group FL and SL before the ingestion of HDF diets, the ratio of Firmicutes/Bacteroidetes in them was much higher than that in Group FO and SO (P $<0.01$ ). After the consumption of high-dietary-fiber diets, the ratio of Firmicutes/Bacteroidetes in all groups decreased, from $0.76 \pm$ 0.45 to $0.04 \pm 0.01$ of Group SL ( $<<0.01), 0.18 \pm 0.14$ to $0.09 \pm 0.06$ of Group SO (P<0.05), from $0.76 \pm 0.44$ to $0.04 \pm 0.01$ of Group FL $(\mathrm{P}<0.01)$ and $0.18 \pm 0.14$ to $0.08 \pm 0.01$ of Group FO $(\mathrm{P}<0.05)$, but the ratio in Group SL and FL was lower than that in Group SO and FO. Furthermore, Group FL and SL were also found to gain more BW than Group SO and FO in the end. The present study investigated the role of gut microbiota, mainly Firmicutes and Bacteroidetes in energy harvest by feeding two high-dietary-fiber (HDF) diets to lean and obese rats at the same time. After ingesting HDF diets for 8 weeks, both obese and lean rats continuously gained their body weight, but the lean rats gained more weight than the obese ones in two HDF diets. In the meanwhile, the ratio of Firmicutes to Bacteroidetes decreased in all groups and became lower in lean rats. 

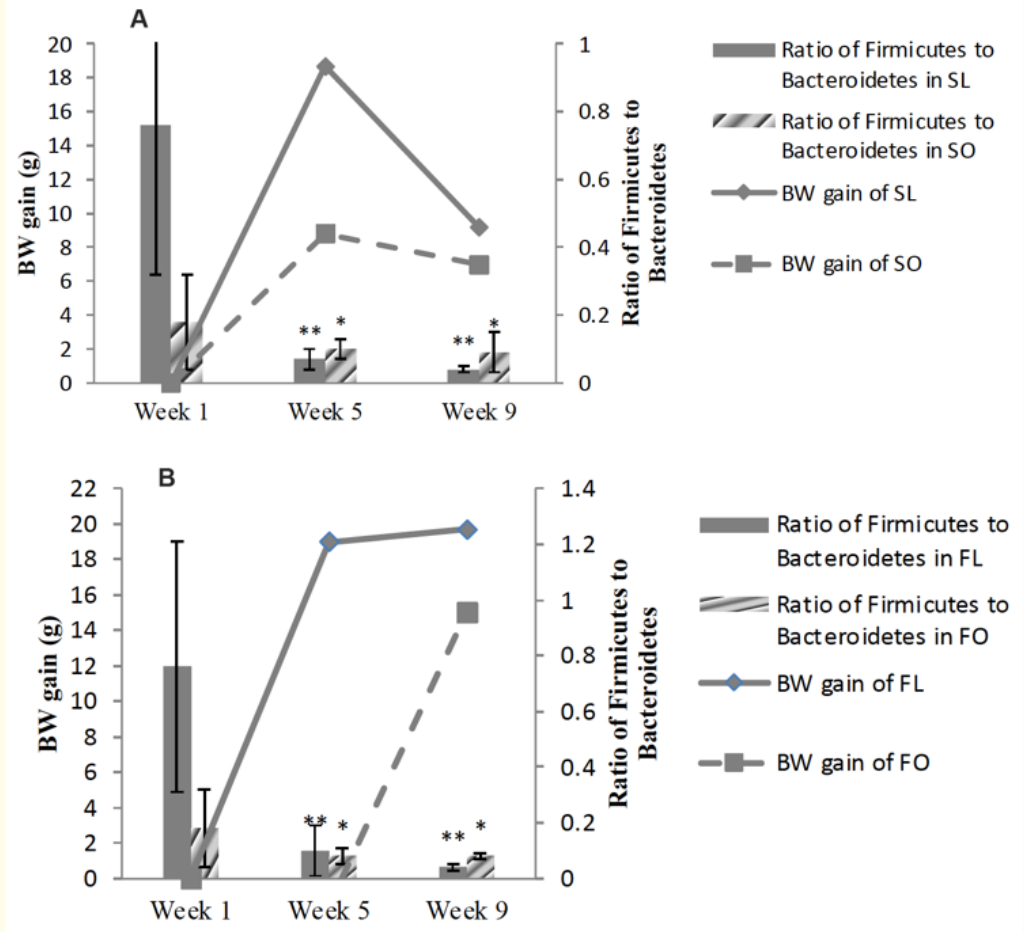

Figure 1: Relationship between rats' BW gain and ratio of Firmicutes to Bacteroidetes.

Relationship between total SCFAs and bacteroidetes abundance

Total SCFAs, including acetic, propionic and butyric, and the abundances of Bacteroidetes in all groups were presented in figure 2. A similar tendency was found between the concentration of total SCFAs and the abundance of Bacteroidetes in feces. During the period of treatment with FOS and SF, the relative abundance of Bacteroidetes increased in all groups, and the concentration of SCFAs in feces also rose up except the minor fluctuation in Group SL.

Several studies about obese mice and humans have reported significant shifts in the intestinal phyla with an increase in Firmicutes and a reduction in Bacteroidetes $[15,16]$. Thus, it was believed that these changes resulted in an increased capacity for the fermentation of carbohydrates. Besides released monosaccharides, SCFAs are the end products of polysaccharides hydrolyzed by enzymes from gut microbiota and can be absorbed as energy by host $[17,18]$. Our results presented those lean rats are growing more Bacteroidetes in feces, gained more BW from the same HDF diets than obese rats. Furthermore, more total SCFAs were produced in lean rats (Figure 2). Bacteroides spp. is known to break down a wide variety of indigestible dietary plant polysaccharides (e.g., amylose, amylopectin, and pullulan) [19]. In our experiments, the concentration of SCFAs in feces increased when the abundance of Bacteroidetes was elevated by rats' consumption of HSF or HFOS diets, which was also consistent with previous study [20]. Our results demonstrated Bacteroidetes' better ability of hydrolyzing plant saccharides.

Relationship between LPS and abundance of bacteroidetes and proteobacteria

The change tendencies of plasma LPS and abundance of Gramnegative bacteria including Bacteroidetes and Proteobacteria were compared in figure 3. When the abundance of Gram-negative bacteria decreased, the plasma LPS level was found to decrease too in all groups. The abundance of Bacteroidetes and Proteobacteria in lean rats was significantly higher than that in obese rats $(\mathrm{P}<0.01)$, and higher plasma LPS level $(\mathrm{P}<0.05)$ was also found in lean rats before all rats ingested HDF diets. In group SO and FO, no significant alteration in the abundance of Bacteroidetes and Proteobacteria was presented, and only a little fluctuation of LPS level was detected. But in group SL and FL, their abundance of Bacteroidetes 

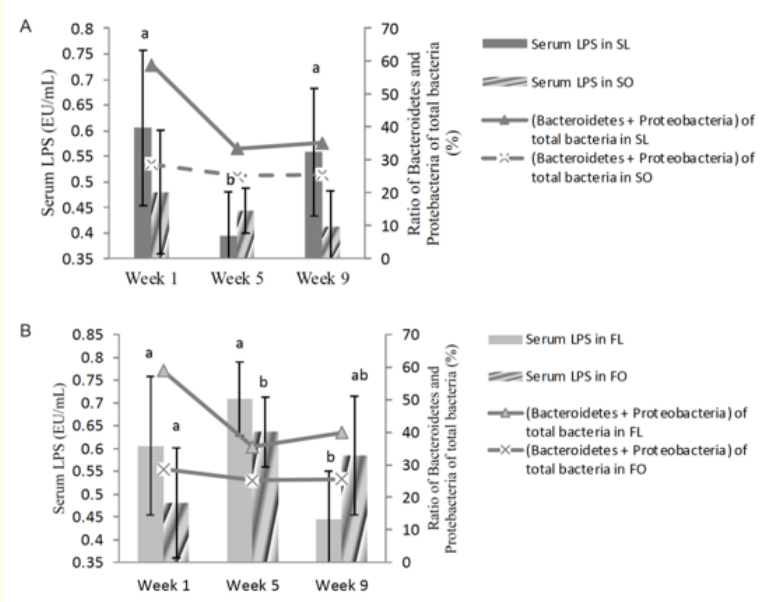

Figure 2: Relationship between rats' fecal SCFAs level and abundance of Bacteroidetes.

and Proteobacteria was as high as $58.92 \%$ at week 0 and decreased to $35.13 \%$ and $39.82 \%$ at week 8; the plasma LPS of group SL decreased at week 4 , whereas that of group FL still stayed in relatively high level at week 4, but finally decreased at week 8 .

LPS is a compound from Gram-negative bacteria cell walls, and its concentration is up along with an increase in the proportion of Gram-negative bacteria induced by a fat-rich diet [21,22]. In both studies of humans and mice, positive correlations have been found between energy harvest and plasma LPS level [21,22]. In our results, the plasma LPS levels were decreased along with the reducing abundance of two main phyla of Gram-negative bacteria in gut, Bacteroidetes and Proteobacteria, which agreed with the previous studies. Therefore, even though two DF-rich diets didn't inhibit rats' BW gains, but they reduced gram-negative bacteria in gut and hence lowered down plasma LPS level.

\section{Relationship between BW gain and plasma leptin level}

The plasma leptin level in Group SO and FO was significantly higher than that in Group SO and FO (867.76 vs. 698.700 P < 0.05) (Figure 4) at the beginning of experiment. When these rats ingested the high-dietary-fiber diets, the rats' plasma leptin level decreased along with their BW gain $(\mathrm{P}<0.05)$ at the first 4 weeks. As group SL and FL gained more BW than group SO and FO (data not shown, $\mathrm{P}<0.05$ ) at the second 4 weeks, the leptin level in Group SL and

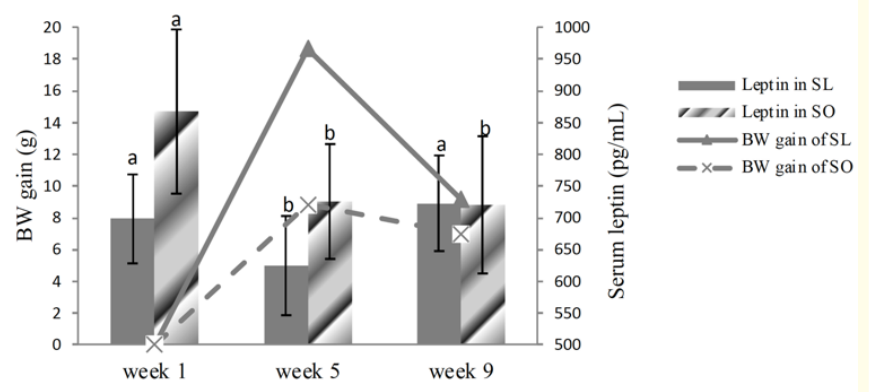

Figure 3: Relationship between rats' plasma LPS level and abundance of Bacteroidetes and Proteobacteria in total bacteria.

FL was found significantly increased $(\mathrm{P}<0.05)$. The plasma leptin level in Group SO and FO did not present significant alteration from week 4 to week 8.

Leptin is a multifunctional hormone that is reported as a starvation signal and can regulate body weight, energy homeostasis [23]. Queipo-Ortuño, Seoane, Murri, Pardo, Gomez-Zumaquero, Cardona, Casanueva and Tinahones [24] has reported that a significant positive correlation between the quantity of Bifidobacterium and Lactobacillus and serum leptin levels, and a significant and negative correlation among the number of Clostridium, Bacteroides and Prevotella and serum leptin levels in all experimental groups. Our results showed that as lean rats gained more BW than obese rats, their plasma leptin were found significantly increased from week 4 to week 8, while no significant alteration was found in obese rats. The increased leptin level demonstrated that lean rats ingested more energy from the HDF diets. It was accordant with the previous reports that leptin is a starvation signal, and its secretion is to reduce host's energy harvest [25]. Since lean rats grew more than obese ones, they need to secrete more plasma leptin level to reduce the absorption of energy.

\section{Conclusion}

HDFs can significantly down-regulate the ratio of Firmicutes to Bacteroidetes from 0.76 to 0.04 in lean rats' gut and from 0.18 to 0.09 or 0.08 in obese rats' gut $(\mathrm{P}<0.01$ or $\mathrm{P}<0.05)$. It was observed that lean rats gained more body weight, about $12.07 \mathrm{~g}$ body weight when consuming a high-soybean-fiber diet, and $25.25 \mathrm{~g}$ body weight when consuming a high-FOS diet, than the obese ones 


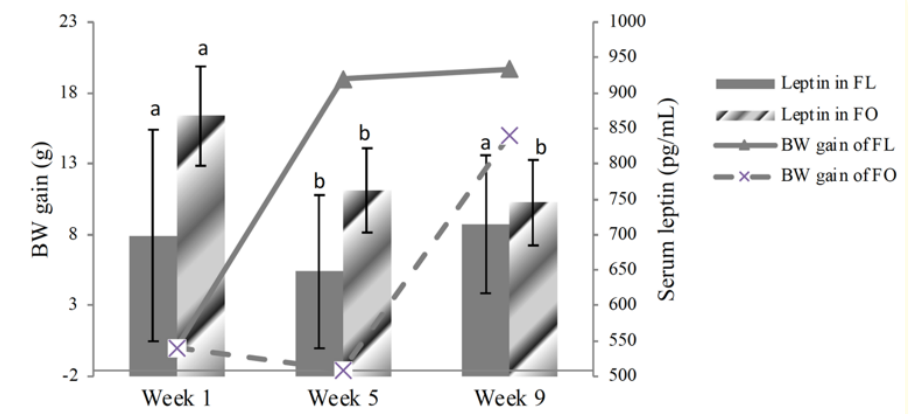

Figure 4: Relationship between rats' BW gain and plasma leptin level.

when they both consumed the same HDF diets. Furthermore, the results also presented the positive relationship of Bacteroidetes and SCFAs, and the fluctuations of plasma LPS and leptin individually kept consistent with that of the abundance of Gram-negative bacteria in feces and rats' BW gain. Hence, Bacteroidetes in gut is the key one to help hosts harvest more energy from HDFs diet.

\section{Compliance with Ethical Standards}

The authors claim no conflicts of interest.

\section{Ethical Approval}

All applicable international, national, and institutional guidelines for the care and use of animals were followed.

\section{Bibliography}

1. I Vaneckova., et al. "Obesity-related hypertension: possible pathophysiological mechanisms". Journal of Endocrinology 223.3 (2014): R63-R78.

2. BE Sansbury and BG Hill. "Regulation of obesity and insulin resistance by nitric oxide". Free Radical Biology and Medicine 73 (2014): 383-399.

3. G De Pergola and F Silvestris. "Obesity as a major risk factor for cancer”. Journal of Obesity 2013 (2013): 291546.

4. K Al-Assal., et al. "Gut microbiota and obesity". Clinical Nutrition Experimental 20 (2018): 60-64.

5. S Stojanov., et al. "The influence of probiotics on the Firmicutes/Bacteroidetes ratio in the treatment of obesity and inflammatory bowel disease". Microorganisms 8.11 (2020): 1715.
6. M Diamant., et al. "Do nutrient-gut-microbiota interactions play a role in human obesity, insulin resistance and type 2 diabetes?" Obesity Reviews 12.4 (2011): 272-281.

7. AK Benson., et al. "Individuality in gut microbiota composition is a complex polygenic trait shaped by multiple environmental and host genetic factors". Proceedings of the National Academy of Sciences 107.44 (2010): 18933-18938.

8. H Yanagi., et al. "Changes in the gut microbiota composition and the plasma ghrelin level in patients with Helicobacter pylori-infected patients with eradication therapy". BMJ Open Gastroenterology 4.1 (2017): e000182.

9. PJ Turnbaugh., et al. "An obesity-associated gut microbiome with increased capacity for energy harvest". Nature 444.7122 (2006): 1027-1031.

10. AR Moschen., et al. "Dietary factors: major regulators of the gut's microbiota". Gut and Liver 6.4 (2012): 411.

11. Y-H Chen., et al. "Housing condition-associated changes in gut microbiota further affect the host response to diet-induced nonalcoholic fatty liver". The Journal of Nutritional Biochemistry 79 (2020): 108362.

12. MJ Khan., et al. "Role of gut microbiota in the aetiology of obesity: proposed mechanisms and review of the literature". Journal of Obesity 2016 (2016): 7353642.

13. S Li., et al. "Lean rats gained more body weight from a highfructooligosaccharide diet". Food and Function 6.7 (2015): 2315-2321.

14. JM Campbell., et al. "Selected indigestible oligosaccharides affect large bowel mass, cecal and fecal short-chain fatty acids, pH and microflora in rats". The Journal of Nutrition 127.1 (1997): 130-136.

15. EM Dewulf., et al. "Insight into the prebiotic concept: lessons from an exploratory, double blind intervention study with inulin-type fructans in obese women". Gut 62.8 (2013): 11121121.

16. NA Ismail., et al. "Frequency of Firmicutes and Bacteroidetes in gut microbiota in obese and normal weight Egyptian children and adults". Archives of Medical Science: AMS 7.3 (2011): 501. 
17. X Li., et al. "Dynamic digestion of tamarind seed polysaccharide: Indigestibility in gastrointestinal simulations and gut microbiota changes in vitro". Carbohydrate Polymers 239 (2020): 116194.

18. G Den Besten., et al. "The role of short-chain fatty acids in the interplay between diet, gut microbiota, and host energy metabolism". Journal of Lipid Research 54.9 (2013): 2325-2340.

19. ND Schwalm III and EA Groisman. "Navigating the gut buffet: control of polysaccharide utilization in Bacteroides spp". Trends in Microbiology 25.12 (2017): 1005-1015.

20. G Jakobsdottir., et al. "High-fat diet reduces the formation of butyrate, but increases succinate, inflammation, liver fat and cholesterol in rats, while dietary fibre counteracts these effects". PloS One 8.11 (2013): e80476.

21. J Chen., et al. "Diet effects in gut microbiome and obesity". Journal of Food Science 79.4 (2014): R442-R451.

22. EG Pérez-Hernández., et al. "New insights into lipopolysaccharide inactivation mechanisms in sepsis". Biomedicine and Pharmacotherapy 141 (2021): 111890.

23. F Hu., et al. "Hypothalamic roles of mTOR complex I: integration of nutrient and hormone signals to regulate energy homeostasis". American Journal of Physiology-Endocrinology and Metabolism 310.11 (2016): E994-E1002.

24. MI Queipo-Ortuño., et al. "Gut microbiota composition in male rat models under different nutritional status and physical activity and its association with serum leptin and ghrelin levels". PloS One 8.5 (2013): e65465.

25. P Mancuso., et al. "Leptin corrects host defense defects after acute starvation in murine pneumococcal pneumonia". American Journal of Respiratory and Critical Care Medicine 173.2 (2006): 212-218.

\section{Assets from publication with us}

- Prompt Acknowledgement after receiving the article

- Thorough Double blinded peer review

- Rapid Publication

- Issue of Publication Certificate

- High visibility of your Published work

Website: www.actascientific.com/

Submit Article: www.actascientific.com/submission.php

Email us: editor@actascientific.com

Contact us: +919182824667 


\begin{tabular}{|c|c|c|c|c|c|c|}
\hline Treatments & Variety & Moisture & C. protein* & Crude fat $^{*}$ & Ash $^{*}$ & T. Carbohyd* $^{*}$ \\
\hline \multirow{3}{*}{ Control } & DV-9 & $5.17 \pm 0.03^{\mathrm{b}}$ & $38.74 \pm 1.39^{\mathrm{c}}$ & $35.46 \pm 0.26^{\mathrm{g}}$ & $9.88 \pm 0.07^{\mathrm{c}}$ & $10.75 \pm 0.25^{\mathrm{h}}$ \\
\cline { 2 - 7 } & G-4 & $4.33 \pm 0.04^{\mathrm{f}}$ & $29.59 \pm 0.80^{\mathrm{h}}$ & $36.89 \pm 0.15^{\mathrm{e}}$ & $10.11 \pm 0.10^{\mathrm{a}}$ & $19.08 \pm 0.09^{\mathrm{d}}$ \\
\cline { 2 - 7 } & G-150 & $4.17 \pm 0.06^{\mathrm{h}}$ & $29.73 \pm 1.22^{\mathrm{f}}$ & $37.26 \pm 0.26^{\mathrm{d}}$ & $9.70 \pm 0.10^{\mathrm{e}}$ & $19.14 \pm 0.36^{\mathrm{c}}$ \\
\hline \multirow{2}{*}{ Whole 15' } & DV-9 & $4.89 \pm 0.30^{\mathrm{d}}$ & $39.06 \pm 0.12^{\mathrm{b}}$ & $34.21 \pm 0.04^{\mathrm{i}}$ & $9.74 \pm 0.04^{\mathrm{d}}$ & $12.10 \pm 0.50^{\mathrm{g}}$ \\
\cline { 2 - 7 } & G-4 & $4.26 \pm 0.12^{\mathrm{g}}$ & $29.30 \pm 1.48^{\mathrm{i}}$ & $35.31 \pm 0.66^{\mathrm{h}}$ & $9.91 \pm 0.03^{\mathrm{b}}$ & $21.22 \pm 0.29^{\mathrm{a}}$ \\
\cline { 2 - 7 } & G-150 & $4.44 \pm 0.18^{\mathrm{e}}$ & $29.62 \pm 0.59^{\mathrm{g}}$ & $36.10 \pm 0.28^{\mathrm{f}}$ & $9.55 \pm 0.04^{\mathrm{f}}$ & $20.29 \pm 0.09^{\mathrm{b}}$ \\
\hline \multirow{2}{*}{ Dehulled 15' } & DV-9 & $5.56 \pm 0.05^{\mathrm{b}}$ & $41.11 \pm 0.37^{\mathrm{a}}$ & $39.65 \pm 0.21^{\mathrm{c}}$ & $5.81 \pm 0.02^{\mathrm{i}}$ & $7.87 \pm 0.35^{\mathrm{i}}$ \\
\cline { 2 - 7 } & G-4 & $4.97 \pm 0.17^{\mathrm{c}}$ & $32.84 \pm 0.99^{\mathrm{d}}$ & $40.79 \pm 0.04^{\mathrm{b}}$ & $6.48 \pm 0.13^{\mathrm{g}}$ & $14.92 \pm 0.33^{\mathrm{e}}$ \\
\cline { 2 - 7 } & G-150 & $5.31 \pm 0.31^{\mathrm{a}}$ & $32.46 \pm 0.82^{\mathrm{e}}$ & $42.05 \pm 0.35^{\mathrm{a}}$ & $5.94 \pm 0.01^{\mathrm{h}}$ & $14.28 \pm 0.49^{\mathrm{f}}$ \\
\hline
\end{tabular}

Table 5: Proximal analysis of selected treatments for sesame seeds variety DV-9, G-4 and G-150.

Diets rich in plant products have become popular in recent times due to both the supply of essential nutrients and chemical compounds with health-promoting characteristics, such as vitamins and antioxidants. A diet rich in whole grains and plant foods, low in total fat but high in soluble fibers and monounsaturated and polyunsaturated fatty acids, reduces the risk of chronic non-communicable diseases [1]. This food group includes sesame seeds, which have various nutritional properties [2]. Sesame, whose scientific name is Sesamum indicum L., belongs to the Pedaliaceae family, which is composed of 16 genera and 60 species [3]. Sesame is grown in tropical and subtropical regions on just over seven million hectares to produce six million tonnes per year [4]. The demand for sesame seed has increased every year due to commercial and industrial interest in the high oil content. Myanmar, India and China are now the world's leading producers, followed by Sudan, Nigeria, Ethiopia and Uganda. In America the largest producers are: Mexico, Guatemala, and Venezuela [4]. Sesame is used for the production of edible oil, margarines (it is appreciated in countries that consume it for its pleasant taste and being easily digestible), as an ingredient in the pharmaceutical industry, in the manufacture of soaps, cosmetics and paints. After the extraction of the oil, the residual part (cake) remains, useful for feeding livestock and poultry. It contains 40 to $50 \%$ protein. Sesame seed is used in the preparation of biscuits and confectionery [5,6]. The term antinutrients areis used to qualify those compounds that affect the nutritional value of some foods, especially seeds, because they hinder or inhibit the assimilation of nutrients that come from foods generally of plant origin (proteins and minerals), from the biochemical point of view these factors are of varied nature and can become toxic or cause undesirable physiological effects such as flatulence, Stomach distension, pancreatic affectations, agglutination of red blood cells, decrease in the assimilation of nutrients, among others, antinutritional factors are natural non-fibrous substances, generated by the secondary metabolism of plants as a defense mechanism to stressful situations or against the attack of moulds, bacteria, insects and birds [1,7]. Authors have [8] evaluated the effect of various treatments on the anti-nutritional factors of both whole and dehulled varieties of sesame seeds in Nigeria and observed that the use of water soaking, germination, autoclaving, roasting and cooking significantly reduced the levels of phytates and oxalates in whole and dehulled sesame seeds, with a maximum reduction in these levels

1. Martínez M. "Antinutrientes proteicos de las leguminosas: tipos, toxicidad y efectos fisiológicos". Trabajo de grado en $\mathrm{Nu}$ trición Humana y Dietética, Universidad de Valladolid (2016).

2. Gómez L and Nader M. "Productos elaborados con semillas de chía y sésamo: composición química, aceptabilidad, satisfacción y conocimiento sobre sus propiedades nutricionales". Actualización en Nutrición 13 (2012): 250-267.

3. Pineda M. "Respuesta del cultivo de ajonjolí (Sesamum indicum L, Pedaliaceae) a la fertilización al suelo y foliar en Aldea El Paredón Buena Vista, La Gomera, Escuintla, Guatemala”. Tesis de Ingeniero Agrónomo, Universidad Rafael Landiva (2009).

4. FAO. "Production statistics". FAO, Rome, Italy (2016).

5. Cruz E. "La importancia del cultivo de ajonjolí (Sesamum indicum L.) en México". Monografía de Ingeniero Agrónomo, Universidad Autónoma Agraria Antonio Narro (2003). 
6. Anilakumar K., et al. "Nutritional, medicinal and industrial uses of sesame (Sesamum indicum L.) seeds". Agriculturae Conspectus Scientificus 75 (2010): 159-168.

7. Elizalde A., et al. "Factores antinutricionales en semillas". Facultad de Ciencias Agropecuarias, 7 (2009): 45-54.

8. Makinde F and Akinoso R. "Nutrient composition and effect of processing treatments on anti nutritional factors of Nigerian sesame (Sesamum indicum Linn) cultivars". International Food Research Journal 20 (2013): 2293-2300.

9. Olagunju A and Ifesan B. "Changes in nutrient and antinutritional contents of sesame seeds during fermentation". Journal of Microbiology, Biotechnology and Food Sciences 2 (2013): 2407-2410.

10. Association of Official Analytical Chemist AOAC. "Official methods of analysis". 15th edition. Washington DC: Association of Official Analytical Chemists (2010).

11. ElKhori S., et al. "The microwave-assisted process (MAPTM1): Extraction and determination of fat from cocoa powder and cocoa nibs". Journal of Food Engineering 79 (2007): 11101114.

12. Obadoni B and Ochuko P. "Phytochemical Studies and Comparative Efficacy of the Crude Extracts of Some Homeostatic Plants in Edo and Delta States of Nigeria". Global Journal of Pure and Applied Science 8 (2001): 203-208.

13. Rodríguez J. “Determinación y cuantificación de saponinas en las hojas de la cabuya (Furcraea andina) para su posible uso como tensoactivo en detergentes biodegradables". Trabajo de grado de Químico y Farmacéutico, Universidad de Guayaquil (2017).

14. Wheeler EL and Ferrel RE. "A method for phytic acid determination in wheat fractions". Cereal Chemistry 48 (1971): 312316.

15. Kayode R., et al. "Physico-chemical and antinutritional characterization of the kernels of some mango (Mangifera indica) cultivars grown in Western parts of Nogeria". Food Science and Quality Management 22 (2013): 1-8.
16. Underwood G. "Quantitative Analysis". 5th ed. Prentice Hall Publication, London (1986).

17. Montilla D and Terán H. "UCLA-1, una nueva variedad de ajonjolí (Sesamum indicum L.)”. Bioagro 8 (1996): 26-29.

18. Gómez J. "Efecto de la concentración de ajonjolí (Sesamum indicum) sobre las propiedades nutricionales, sensoriales y reológicas de un producto untable de cacao (Theobroma cacao L.)". Trabajo especial de grado de Licenciatura, Universidad Central de Venezuela ( 2018).

19. Ogungbenle $\mathrm{H}$ and Onoge $\mathrm{F}$. "Nutrient composition and functional properties of raw, defatted and protein concentrate of sesame (Sesamum indicum) flour". European Journal of Biotechnology and Bioscience 2 (2014): 37-43.

20. Momoh A., et al. "The effects of different treatments on the phytochemicals, proximate, and mineral contents of beniseeds (Sesamum indicum Linn)". Global Advanced Research Journal of Biotechnology 1 (2012): 008-011.

21. Khashaba A., et al. "Effect of some heat treatments on chemical composition and oil characteristics of sesame seeds (Sesamum indicum L.)". Journal of Food and Dairy Science 5 (2014): 701716.

22. Jimoh W., et al. "Effect of processing on some minerals, antinutrients and nutritional composition of sesame (Sesamum indicum) seed meals". Electronic Journal of Environmental, Agricultural and Food Chemistry 7 (2011): 79-85.

23. Nwobasi C and Attamah C. "Proximate analysis and phytochemical properties of sesame (Sesamum indicum L.) seeds grown and consumed in Abakaliki, Ebonyi state, Nigeria". International Journal of Health and Medicine 2 (2017): 1-4.

24. Chocrón S. "Evaluación nutricional de sucedáneo de yogur elaborado a partir de ajonjolí (Sesamum indicum L.)". Trabajo especial de grado de Licenciatura, Universidad Central de Venezuela (2018).

25. Bello F., et al. "Evaluation of some antinutritional factors in oilfree white Sesamum indicum L. seed cake". International Journal of Food Nutrition and Safety 4 (2013): 27-33. 
26. Okoronkwo N., et al. "Assessment of potential values of Sesamum indicum seed". International Journal of Arts and Sciences 07 (2014): 19-27.

27. Nwalo N. "Genetic diversity of Nigerian Sesame cultivars (Sesamum indicum L) based on simple sequence repeat (SSR) markers and its relationship with phytochemicals". International Journal of Current Microbiology and Applied Sciences 4 (2015): 898-908.

28. Ridout C., et al. "Quinoa saponins-analysis and preliminary investigations into the effects of reduction by processing". Journal of the Science of Food and Agriculture 54 (1991): 165-176.

29. Quispe F., et al. "A Kinetic approach to saponin extraction during washing of quinoa (Chenopodium quinoa Willd.) seeds". Journal of Food Process Engineering 36 (2013): 1-9.

30. Oenning G., et al. "Degradation of oat saponins during heat processing - effect of $\mathrm{pH}$, stainless steel, and iron at different temperatures". Journal of Agricultural and Food Chemistry 42 (1994): 2578-2582.

31. Güçlü Ü and Mazza G. "Saponins: Properties, Applications and Processing". Critical Reviews in Food Science and Nutrition 47 (2007): 231-258.

32. Ahumada A., et al. "Saponinas de quinua (Chenopodium quinoa Willd.): un subproducto con alto potencial biológico". Revista de Ciencias Químico-Farmacéuticas 45 (2016): 438-469.

33. Makinde $\mathrm{F}$ and Akinoso R. "Comparison between the nutritional quality of flour obtained from raw, roasted and fermented sesame (Sesamum indicum L.) seed grown in Nigeria". Acta Scientiarum Polonorum 13 (2014): 309-319.

34. Okudu H., et al. "Nutrients and anti-nutrients contents of white beniseed cultivar (Sesamum indicum L.) in nigeria". Direct Research Journal of Agriculture and Food Science 4 (2016): 290293.

35. Chichester C., et al. "Advances in food research". Academic Press. USA. (1982).

36. Abbas $Y$ and Ahmad A. "Impact of processing on nutritional and antinutritional factors of legumes: a review". Annals of Food Science and Technology 19 (2018): 199-215.
37. Thompson LU. "Potential health benefits and problems associated with antinutrients in foods". Food Research International 26 (1993): 131-149.

38. Febles C. "Estudio del contenido de fitatos enderivados de cereales de consumo en canarias". Tesis Doctoral, Universidad de la Laguna. (1998).

39. Greiner R and Konietzny U. "Improving enzymatic reduction ofmyo-inositol phosphates with inhibitory effects on mineral absorption in black bean (Phaseolus vulgaris var. Preto)". Journal of Food Processing and Preservation 23 (1999): 249-261.

40. Afify A., et al. "Bioavailability of iron, zinc, phytate and phytase activity during soaking and germination of white sorghum varieties". PLoS ONE 6 (2011): e25512.

41. Gupta R., et al. "Reduction of phytic acid and enhancement of bioavailable micronutrients in food grains". Journal of Food Science and Technology 52 (2015): 676-684.

42. Chang R., et al. "Phytate removal from whole dry beans by enzymatic hydrolisis and diffusion". Journal of Food Science 42 (1977): 1098-1101.

43. Lestienne I., et al. "The effects of soaking of whole, dehulled and ground millet and soybean seeds on phytate degradation and Phy/Fe and Phy/Zn molar ratios". International Journal of Food Science and Technology 40 (2005): 391-399.

44. Reddy N and Salunkhe D. "Interactions between phytate, protein, and minerals in whey fractions of black gram". Journal of Food Science 46 (1981): 564-567.

45. Bishnoi S., et al. "Effect of domestic processing and cooking methods on phytic acid and polyphenol contents of pea cultivars (Pissm sativum)". Plant Foods for Human Nutrition 45 (1994): 381-388.

46. Manikantan M., et al. "Selection of process parameters for producing high quality defatted sesame flour at pilot scale". Journal of Food Science and Technology 52 (2015): 1778-1783.

47. Singh $P$ and Saxena N. "Variation in oxalate and mineral contents of Bathua Vegetables collected from different sites". Indian Journal of Nutrition and Dietetics 10 (1973): 84-90. 
48. Faheed F., et al. P"hysiological and ultrastructural studies on calcium oxalate crystal formation in some plants". Turkish Journal of Botany 37 (2013): 139-152.

49. Polli A., et al. "Structural development of the fruits and seeds in three mistletoe species of Phoradendron (Visceae: Santalaceae)". Rodriguésia 67 (2016): 649-659.

50. Irudayaraj A., et al. "Synthesis, growth and characterization of semi-organic crystal: potassium hydrogen oxalate dihydrate". International Journal of Recent Scientific Research 6 (2015): 2732-2736. 